\title{
Does continuing medical education improve general practitioners' knowledge and practice on management of fever without a focus and dengue fever in children?
}

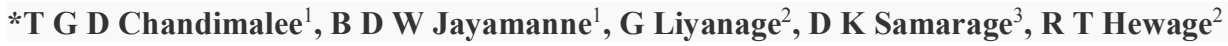 \\ Sri Lanka Journal of Child Health, 2017; 46(4): 353-356
}

\begin{abstract}
Introduction: Fever is a common symptom in children and is a cause of great anxiety for parents and caregivers. The improvement in patient comfort appears to be a key therapeutic objective in busy general practices. However, nonsteroidal antiinflammatory drugs (NSAIDs) in any form and steroids are best avoided especially in patients with fever without a focus. Sri Lanka has been witnessing an increase in dengue fever incidence over the years. Disease manifestations of dengue fever are complex and management is comparatively simple. However, lack of knowledge and erroneous practice at primary care level in managing these children could lead to increase morbidity and mortality.
\end{abstract}

Objective: To assess the current practice of a group of GPs management of children with fever without a focus and dengue fever, to determine whether this practice is in accordance with available guidelines and to assess the value of educational programmes on strengthening knowledge and practice.

Method This was an experimental, pre-test and posttest design study carried out at the Colombo South Teaching Hospital (CSTH). General Practitioners (GPs) from health divisions in close proximity to CSTH were invited for the study. The enrolled GPs were given a pre-piloted questionnaire. A seminar was conducted on management of fever without a focus and dengue fever for all who took part in the study and information, education, communication (IEC) material were given to all participants. Participant GPs were assessed by a post-test questionnaire. All the data were entered into an electronic format (spreadsheet) and analysed using SPSS version 16.

\footnotetext{
${ }^{1}$ Ministry of Health, Colombo, Sri Lanka, ${ }^{2}$ Faculty of Medical Sciences, University of Sri Jayawardenapura, ${ }^{3}$ Faculty of Medicine, South Asian Institute of Technology and Medicine

*Correspondence: dcthennakoon@gmail.com

(Received on 08 March 2017: Accepted after revision on 17 April 2017)

The authors declare that there are no conflicts of interest

Personal funding was used for the project.

Open Access Article published under the Creative
}

Commons Attribution CC-BY License
Results: A total of 93 GPs participated in the study. Response rate for the pre-test and post-test questionnaires were $93 \%$ and $78 \%$ respectively. Before intervention overall median score was 75.68 (IQR-16.22) and after intervention overall median score was 85.14 (IQR-13.51), p value $<0.001$. Median scores of each knowledge component for managing dengue fever showed an improvement with intervention.

Conclusions: This study has clearly shown improvement of knowledge and perception on febrile phase management of dengue fever.

DOI: http://dx.doi.org/10.4038/sljch.v46i4.8383

(Key words: Fever without a focus, fever management, febrile illnesses, antipyretics, dengue fever, General practitioners)

\section{Introduction}

Fever is a common symptom in children and is a cause of great anxiety for parents and caregivers. It brings many fears to the surface, most of which are unfounded. It is unfortunate that parents have perceived temperature reduction as the primary goal, perhaps at the expense of more important issues when a child develops fever. The reaction of the health professional may reinforce these concerns, particularly if the nature of fever and its significance is not properly communicated and if fever is managed as an illness rather than a symptom.

Paracetamol and non-steroidal anti-inflammatory drugs (NSAIDs) such as ibuprofen and diclofenac sodium effectively reset the 'central thermostat' when used alone or in combination ${ }^{1}$. Overall wellbeing that parents and clinicians see in the child's condition strongly reinforces the practice of giving NSAIDs. This improvement in patient comfort appears to be a key therapeutic objective in busy general practices. Parents fear that their child may have convulsions with high fever. However, studies have shown that chance of occurrence of recurrent febrile convulsions is not reduced by antipyretics ${ }^{2}$. Further, with dengue endemicity and surges in the case load at certain times of the year, use of NSAIDs cannot be recommended in Sri Lanka. 
Dengue is a major public health problem in tropical and subtropical regions of the world ${ }^{3}$. Sri Lanka has been witnessing its increase in incidence over the years. Disease manifestations of dengue fever are complex. However, management is comparatively simple ${ }^{4}$. It is effective in saving many lives if timely intervention is done.

For these patients with fever, first contact would be at general practice/primary care or out-patient departments of both public and private sectors. General practice is in fact an optional facility for those who can afford and it is used by half the population $^{5}$. A preliminary audit at the Colombo South Teaching Hospital (CSTH) showed that $69 \%$ of patients have taken treatment from General Practitioners (GPs) prior to admission to hospital. Evidence based knowledge on management of fever is essential at this level of care. Further, being alert and understanding changes that occur in different phases of dengue fever especially by the primary care practitioner is important in reducing mortality, morbidity and reducing the number of unnecessary hospital admissions ${ }^{5}$.

In general practice, educational activity should be based on the work that doctors do. It has been highlighted in many studies that group and peer review type interventions are shown to be feasible and effective ${ }^{6,7}$. Thus, a continuing medical education programme for GPs is an essential component.

\section{Objectives}

To assess the current practice of a group of GPs management of children with fever without a focus and dengue fever, to determine whether this practice is in accordance with available guidelines and to assess the value of educational programmes on strengthening knowledge and practice.

\section{Method}

This was an experimental, pre-test and post-test design study conducted at $\mathrm{CSTH}$, a tertiary care hospital. Practitioners from health divisions in close proximity to the hospital were invited for the study. Sample calculation was performed based on an unpublished audit. This audit gathered information on management of febrile illnesses and dengue fever by GPs. Based on this information sample size was calculated with $95 \%$ confidence interval and $10 \%$ relative precision.
Written informed consent was taken from the GPs who were willing to participate in the study. Homeopathic and Ayurvedic medical practitioners were excluded. Then, the enrolled GPs (100) were given a pre-piloted questionnaire which was based on available guidelines in management of dengue fever and fever without a focus ${ }^{8,9,10}$. In the second stage, on the same day, a seminar was conducted on management of fever without a focus and dengue fever for all who took part in the study. The seminar included 3 lectures and small group discussions. A pre-recorded video compact disc (VCD) with lectures, a copy of national guidelines on management of dengue fever and information, education communication (IEC) material were given to all participants. In addition, geographic location of each general practitioner surgery was recorded by using a hand held Global Positioning System (GPS) device. One month later, a post-test questionnaire was given. Ethical clearance was obtained from, Ethics Review Committee of CSTH.

\section{Data analysis}

All questionnaires were pre-coded before data entry. Total marks as well as ranked responses were calculated for detailed knowledge assessment. All the data were entered into an electronic format (spreadsheet) and analysed using SPSS version16 statistical package.

\section{Results}

A total of 93 GPs participated in the study. Response rate for the pre-test and post-test questionnaires were $93 \%$ and $78 \%$ respectively. Majority (84\%) were attached to state run hospitals or fee levying hospitals and their general practice was outside their routine duty hours. Fifty percent of all GPs had an additional postgraduate diploma (e.g. Diploma in family medicine) and majority (62.8\%) had more than five years of experience as a GP.

When the pre-test questionnaire responses were analysed, in $92(98.9 \%)$ the first choice of antipyretic was paracetamol. However, 22 (24.1\%) claimed that they use NSAIDs in their practice when fever cannot be controlled with paracetamol. Main reason for prescription of NSAIDs was to bring down the high temperature to reduce parental anxiety. Majority (87.9\%) thought that antibiotics should not be prescribed without clear evidence of bacterial sepsis. There was significant improvement in reduction in use of NSAIDs with the educational programme. (Table I) 
Table I: Level of knowledge and practice on controlling fever without a focus before and after the educational programme

\begin{tabular}{|l|c|c|c|c|}
\hline Area of knowledge / practice & $\begin{array}{c}\text { Before educational } \\
\text { programme (\%) }\end{array}$ & $\begin{array}{c}\text { After educational } \\
\text { programme (\%) }\end{array}$ & $\begin{array}{c}\text { Chi squared } \\
\text { value }\end{array}$ & $\boldsymbol{p}$ value \\
\hline $\begin{array}{l}\text { Avoid use of antibiotics for } \\
\text { fever without a focus }\end{array}$ & 87.90 & 89.10 & 0.41 & 0.839 \\
\hline $\begin{array}{l}\text { Occurrence of febrile } \\
\text { convulsions not related to } \\
\text { height of temperature spike }\end{array}$ & 26.00 & 55.00 & 9.64 & 0.002 \\
\hline $\begin{array}{l}\text { Paracetamol as first line } \\
\text { antipyretic }\end{array}$ & 99.07 & 100.0 & 0.41 & 0.523 \\
\hline $\begin{array}{l}\text { Avoid use of NSAIDs for } \\
\text { control of fever }\end{array}$ & 75.80 & 97.44 & 8.76 & 0.002 \\
\hline
\end{tabular}

Most (76\%) knew the existence of local and WHO guidelines on management of dengue fever. However, only $36.5 \%$ have referred these guidelines for patient management. Significant improvement in knowledge on dengue fever was evident. Before intervention overall median score was 75.68 (Minimum 52.7, maximum 90.54, IQR-16.22) and after intervention: overall median score was 85.14 , (Minimum 74.32, maximum 94.59, IQR-13.51). This was statistically significant $(p<0.001)$.
Median scores for each knowledge component for managing dengue fever before and after intervention was compared using Mann Whitney U test (Table 2). Median scores of each area showed an improvement with intervention. Although improvement was not significant for management of febrile phase and timing of Full Blood Count (FBC), their knowledge on those areas was satisfactory.

Table 2: Level of knowledge and practice managing dengue fever before and after the educational programme

\begin{tabular}{|l|c|c|c|}
\hline Area of knowledge & $\begin{array}{c}\text { Median score before } \\
\text { educational programme }\end{array}$ & $\begin{array}{c}\text { Median score after } \\
\text { educational programme }\end{array}$ & $\boldsymbol{p}$ value \\
\hline When to suspect dengue fever & 2.49 & 4.23 & $<0.001$ \\
\hline Management of febrile phase & 3.19 & 3.15 & 0.879 \\
\hline Differentiation of DF from DHF & 1.42 & 2.88 & $<0.001$ \\
\hline Warning signs identification & 2.91 & 3.77 & $<0.001$ \\
\hline When to refer for hospital admission & 2.33 & 2.87 & 0.012 \\
\hline Risk groups identification & 2.1 & 3.62 & $<0.001$ \\
\hline Timing of Full Blood Count & 0.96 & 1.46 & 0.348 \\
\hline
\end{tabular}

DF- Dengue fever, DHF-dengue haemorrhagic fever

\section{Discussion}

Almost all primary care practitioners claimed that they use NSAIDs in their practices although their first choice was paracetamol in controlling fever. While the main reason for prescription of NSAIDs was to lessen the patient discomfort and to reduce parental anxiety, most GPs knew that NSAIDs are best avoided in dengue fever. However a significant percentage of GPs thought that there is a relationship between high temperature and risk for febrile convulsions, even after the educational session. Parents believe that administration of antipyretics would reduce the risk of further convulsions in at risk children.

Some of these patients with fever without an identifiable focus may have a serious bacterial infection; the risk being greater among infants and young children. Physical examination and patient history do not always identify patients with occult bacteraemia or serious bacterial infection. Therefore, in-depth evaluation of the febrile child and identifying the need for antibiotics, need for hospital admission, laboratory studies and cost effectiveness of prescribed therapy are primary considerations. For its consistent rational management, primary health care practitioners should have evidence based knowledge and positive attitudes to avoid unnecessary use of antibiotics.

Dengue has complex manifestations. Knowledge and rational approach to case management is important at primary healthcare level. This study has clearly shown improvement of knowledge and perception on febrile phase management of dengue fever. If we are to move forward with regard to reduction in mortality rates of dengue fever further, it is important that we need to strengthen educational strategies for primary health care workers. 
Does continuing medical education improve general.... Sri Lanka Journal of Child Health, 2017; 46(4): 353-356

One limitation of our study is that of missing some of the GPs practising in the areas considered due to non-availability of a GP register. We need to strengthen the curative care provided by GPs. An organizational structure and a registry for GPs may improve the efficiency and effectiveness of delivery of care. Maintaining a GP registry in each administrative division will enable authorities for easy access to disseminate knowledge. Further, non-inclusion of Ayurvedic and homeopathic medical practitioners was another limitation of this study. Future studies are recommended to assess the frequency and depth of knowledge that should be imparted to primary care practitioners to sustain good practice.

\section{Conclusions}

This study showed that a significant improvement in knowledge could be made by updating knowledge of GPs through educational programmes to improve standards of care.

\section{Acknowledgments}

We thank all the General Practitioners who participated in the study, Dr. Nimalka Pannila Hetti, Consultant Community Physician, National Dengue Control Unit, Ministry of Health who contributed as a resource person at the seminar and Astron LTD, GlaxoSmithKline Pharmaceuticals LTD and Annoyboy Pictures (Pvt) Ltd which sponsored the educational programme.

\section{References}

1. Autret-Leca E. A general overview of the use of ibuprofen in paediatrics. International Journal of Clinical Practice Supplement 2003; 135: 9-12.

2. Rosenbloom E, Finkelstein Y, AdamsWebber T, Kozer E. Do antipyretics prevent the recurrence of febrile seizures in children? A systematic review of randomized controlled trials and metaanalysis. European Journal of Paediatric Neurology 2013; 17(6):585-8.

https://doi.org/10.1016/j.ejpn.2013.04.008

PMid: 23702315

3. World Health Organisation. Dengue and severe dengue. Available from: http://www.who.int/mediacentre/factsheet s/fs117/en/

4. Fact Sheet - Epidemiology Unit. Available from:

http://www.epid.gov.lk/web/images/pdf/F act_Sheet/fact_sheet_on_dengue_for_prim ary_care_doctors.pdf

5. Varnam M. Primary medical care in Sri Lanka: hospital or general practice? Journal of the Royal College of General Practitioners. 1987; 37:31-3.

PMid: 3668923 PMCid: PMC1710596

6. Stanley I, Al-Shehri A, Thomas P. Continuing education for general practice. 1. Experience, competence and the media of self-directed learning for established general practitioners. British Journal of General Practice 1993; 43:210-4.

PMid: 8347389 PMCid: PMC1372394

7. Cantillon P, Jones R. Does continuing medical education in general practice make a difference? British Medical Journal 1999; 318(7193):1276-9. https://doi.org/10.1136/bmj.318.7193.127 6

PMid: 10231265 PMCid: PMC1115655

8. Baraff LJ, Schriger DL, Bass JW, Fleisher GR, Klein JO, McCracken GH et al. Practice guideline for the management of infants and children 0 to 36 months of age with fever without source. Pediatrics 1993; 92(1):1-12.

https://doi.org/10.1016/s01960644(05)809 91-6

9. General Considerations - World Health Organisation. Available from: http://www.who.int/csr/resources/publicati ons/dengue/001-11.pdf

10. Dengue haemorrhagic fever. Chapter 3. Treatment. Available from: http://www.who.int/csr/resources/publicati ons/dengue/024-33.pdf?ua=1 